\title{
Familias y religiosidad en Santiago de Chile: nuevos significados de prácticas religiosas tradicionales
}

\author{
Families and religiosity in Santiago, Chile: New \\ meanings for traditional religious practices
}

Herminia Gonzálvez Torralbo,* Sofia Larrazabal Bustamante**

Perfiles Latinoamericanos, 27(54) | 2019

DOI: $10.18504 / \mathrm{pl} 2754-015-2019$

Recibido: 7 de mayo de 2017

Aceptado: 23 de julio de 2018

\section{Resumen}

Este artículo desarrolla un análisis de las prácticas religiosas en Santiago de Chile desde un enfoque antropológico. Mediante varias entrevistas, se da cuenta de que la religiosidad se ha revelado como una categoría emergente dentro del trabajo de parentesco concluyendo que las mujeres han sido las encargadas de transmitir las creencias y prácticas religiosas a través de las celebraciones. Como hallazgo se observa que dichas prácticas se transforman conforme los miembros de las familias avanzan en sus respectivos ciclos de vida, dado que las someten a reinterpretaciones y con ello descubren nuevos significados.

Palabras clave: familia, trabajo de parentesco, religiosidad, prácticas religiosas, significados.

\begin{abstract}
This article aims to analyze religious practices in Santiago de Chile from an anthropologic approach. After applying several interviews, we found religiosity as an emergent category within kin work, concluding that women have been responsible for the transmission of beliefs and religious practices through celebrations. A main finding is that these practices are transformed as family members move along in their own life cycles, due to re-interpretations and new meanings discovered.
\end{abstract}

Keywords: family, kin work, religiosity, religious practices, meanings.

* Doctora en Antropología Social y Diversidad Cultural. Académica e Investigadora, Facultad de Derecho y Humanidades, Vicerrectoría académica, Universidad Central de Chile. Investigadora "Otras. Perspectivas Feministas en Investigación Social”, Universidad de Granada | herminiagonzalvez@gmail.com

** Licenciada en Ciencia Política y Relaciones Internacionales (Universidad Alberto Hurtado). Asistente de investigación Proyectos Fondecyt 1160683 y PIA-CIE 160007 | sofialarrazabal@gmail.com 


\section{Introducción ${ }^{1}$}

Las familias en América Latina y en Chile han atravesado muchas transformaciones, en especial en las décadas más recientes (CEPAL, 2008, 2009, 2011; PNUD, 2002, 2013). Si se analiza el vínculo entre las familias y su entorno, o las interpretaciones que las familias hacen de sí mismas, el cambio social es una constante en la mayoría de los trabajos académicos que toman al grupo familiar como unidad de análisis (Thornton, 1985; Reca, 1993; CEPAL, 1994; Ramos, 1998; Allen, 2000; Arriagada, 2002; Valdés, 2007; Valdés \& Valdés, 2005; Valenzuela, Tironi \& Scully, 2006; McDowell \& Fang, 2007; Valdés \& Godoy, 2008; Gutiérrez \& Osorio, 2008; Ferree, 2010; Olavarría, 2014; Gonzálvez, 2015).

Güell (1999) interpreta dicho cambio social como un debilitamiento del pacto tácito entre familia y sociedad debido a factores propios de la modernización (individualización de las personas, desregulación de las instituciones sociales, cambios en los roles femeninos o masculinos, y en la distribución de las tareas del hogar, entre otros). Por su parte Araujo (2005) y Araujo \& Martuccelli (2012) añaden que la familia representa el espacio íntimo de apoyo y protección, cuyo protagonismo no se condice con los recursos materiales y simbólicos de los que ella dispone en relación con su lugar de referente en los proyectos vitales de la mayoría de los chilenos/as. En otras palabras, las diversas transformaciones y permanencias en el país tensionan a las familias que son el espacio donde sus miembros se refugian para sortear esos cambios. A esto podemos añadir que las transformaciones que se dan en las estructuras eclesiales de los distintos credos son también cambios sociales, en la medida en que se trata de una reconfiguración de instituciones que en más de un ámbito han operado como eje de referencia para las comunidades que congregan, además de mostrar una adecuación de patrones, símbolos e interacciones entre sus miembros y entre sus jerarquías, lo que deriva en nuevos sentidos normativos y prácticos. Siguiendo la idea de la familia como un espacio de contención y apoyo ante el cambio, se vuelve interesante observar cómo las familias enfrentan la reproducción de la religiosidad en medio de este contexto de transformación.

1 Agradecemos a la Comisión Nacional de Investigación Científica y Tecnológica de Chile (CONICYT) que financió este estudio a través de los proyectos Fondecyt 11121245 "Las Familias en Santiago de Chile: el trabajo de parentesco y la generación de constelaciones familiares" (2013-2016) y Fondecyt Regular 1160683 "Ser Mujer Mayor en Santiago de Chile: Organización Social de los Cuidados, Feminización del Envejecimiento y Desigualdades acumuladas" (2016-2019), dirigidos ambos por Herminia Gonzálvez Torralbo. 
Así, la interdependencia entre familia y sociedad discutida por los autores mencionados requiere revisitarse constantemente (Walker, 2000), dado que sabemos que las familias son unidades sociales complejas y diversas, e impactadas por la legislación (Ortiz, 2015); las prácticas de género, clase, orientación sexual, nación, edad y etnicidad (Valdés, 2007; Valdés \& Valdés, 2005; McDowell \& Fang, 2007); las posiciones de parentesco (Gonzálvez, 2013, 2015); los usos de las nuevas tecnologías de la información y la comunicación (Salazar, 2005); la crisis de la masculinidad (Ferree, 2010; Olavarría, 2014); la organización social de los cuidados (Daly \& Lewis, 2000), y las prácticas religiosas (Zimmerman, 1973; Thornton, 1985; Wilcox, Chaves \& Franz, 2004; Petts, 2007), entre otras. La familia entonces es un objeto de estudio fructífero de conocimiento y producción científica (Gonzálvez, 2013), y al mismo tiempo es un punto de partida para reflexiones y debates que transcienden el espacio "privado" al cual se le ha confinado tradicionalmente.

Este artículo se enfoca en la interrelación entre familia y religiosidad dentro del contexto de cambio social e ilustra a través de hallazgos cualitativos que las prácticas religiosas se modifican entre generaciones, y que son las mujeres quienes en particular se encargan de la transmisión y conservación de las prácticas religiosas por medio del trabajo de parentesco (Di Leonardo, 1987), englobando así significados culturales que trascienden la fe católica ${ }^{2}$ y dotan de sentido a los miembros de la familia hasta constituirse en parte de sus identidades.

Para ello primero se identificarán algunos hitos que dan sentido a la relevancia del estudio de la religión, la religiosidad y la Iglesia católica como categorías analíticas de las familias en Chile. Enseguida se detallará la metodología utilizada y su respectivo análisis. En un tercer momento se exponen los relatos de vida relacionados con las celebraciones religiosas que han sido reinterpretadas y resignificadas a lo largo de la historia familiar. Y por último se ofrecen las conclusiones que permiten comprobar o refutar la hipótesis y subhipótesis planteadas en este trabajo.

\section{Relevancia del tema, estado de la cuestión y principales hipótesis}

Zimmerman (1973) destaca que todas las religiones han concebido las relaciones familiares como sagradas, más allá de las diferencias que cada religión y unidad familiar puedan tener. Así, el catolicismo ha establecido mediante el derecho canónico los pasos para estandarizar la unidad familiar humana y sus

2 Las autoras de este artículo no desconocen que lo mismo ocurre en otros credos, aunque se recurre al caso del catolicismo como la práctica religiosa más común en Chile. 
relaciones internas: el sacramento del matrimonio como hito fundacional de la familia, y las normas de relación entre esposos, padres e hijos, parientes y con los miembros externos al núcleo familiar. Lenski (1963), por su parte, señala que la religiosidad contiene una expresión interpersonal a través de la asociación institucional (asistir a una iglesia) o social (pertenecer a una comunidad de fieles), lo que genera un vínculo de complemento y reforzamiento con la familia gracias a que la adscripción de los miembros permite la transmisión de valores y significados compartidos Sin embargo, la religiosidad también contiene una expresión personal (por ejemplo, la devoción) que no siempre opera en congruencia con las expresiones colectivas/interpersonales.

Es en este punto donde surge una paradoja: la comúnmente conservadora postura institucional católica respecto a la familia no siempre es compartida por todos los que profesan esa fe, aunque ello no quiere decir que dejen de identificarse con la institución, ni con varias de sus prácticas o con el esquema de valores y significados que les han sido inculcados por medio de la vinculación directa o indirecta con el catolicismo. La religión mantiene su importancia para la vida individual y familiar, pero hay grandes cambios, entre estos la modificación de la autoridad moral de la Iglesia católica como institución (Thornton, 1985).

Existen así católicos que configuran nuevas formas de pareja, parentalidad y parentesco por fuera de los márgenes tradicionales defendidos por su religión, aunque ello no conduce a que dejen de creer en las enseñanzas que su fe les ha transmitido, centrándose más en un sentido personal y no en las reglas morales (Thornton, 1985). Se vuelven posibles celebraciones y ritos que se mantienen en tanto hitos de las familias, pero que son reinterpretados, como, por ejemplo, asistir a misa o celebrar la Navidad. Se dan fenómenos como "creer sin pertenecer" y "creer sin participar"; en el primer caso, quienes creen independientemente de su confesión de fe y, en el segundo, quienes mantienen su confesión de fe sin actividad significativa (Valenzuela, Bargsted \& Somma, 2013).

Esta aparente disociación nos lleva a indagar en cuáles son los aspectos religiosos que se tensionan dentro de la familia, y particularmente a la religiosidad como su aplicación práctica. Frazer (1922), Lenski (1963) y Geertz (2003) han definido a la religión y a la religiosidad. La primera se entiende en este artículo como "un sistema de símbolos que obra para establecer vigorosos, penetrantes y duraderos estados anímicos y motivaciones en los hombres" (Geertz, 2003, p., 89). Y religiosidad como "la práctica, vivencia y observancia de las creencias, principios, normas morales y visión de mundo de una religión” (Cruz, s. f., p., 7). De manera complementaria, en este análisis se retoma el concepto de afiliación o identidad religiosa. Para puntualizar, la religiosidad corresponde a algo "vinculado a actitudes, comportamientos y valores" (McAndrew \& Voas, 2011 , p. 2), en tanto que la afiliación o identidad religiosa es algo "más similar 
a la etnicidad, algo que en su mayoría es parte de la familia, la comunidad o la herencia cultural, en vez de ser algo escogido por las personas" (McAndrew \& Voas, 2011, p. 2). Así, la religiosidad se refiere al grado de compromiso con una creencia, y la afiliación o identidad religiosa a un sentimiento de pertenencia.

Religiosidad y afiliación o identidad religiosa se han incluido en este trabajo por dos motivos. En primer lugar porque los relatos familiares de los entrevistados revelan parte de las tensiones que viven los individuos cuando practican y releen sus propias creencias respecto a la fe católica, mayoritariamente, en un entorno social de cambios en las familias y de las concepciones tradicionales de estas, y marcado por la paradoja de la distancia entre lo que piensan quienes profesan la fe católica y la postura de la Iglesia en determinados temas, de tal modo que los individuos se enfrentan a la creencia y práctica de la fe en dirección distinta a la señalada por la institución.

El segundo motivo es relevante puesto que los relatos indican que existe un trasfondo católico en las familias reconocido en su discurso, pero repensado al cuestionar su práctica. Los entrevistados reconocen un ethos común vinculado a la religión católica, pero este opera en celebraciones como comuniones, matrimonios y navidades más no necesariamente con una profesión diaria de la fe.

Esto quiere decir que los entrevistados son receptores y receptoras pasivos de las transformaciones, permanencias y tensiones que se producen entre la esfera familiar y la religiosa, y de manera individual y/o familiar de las nuevas dinámicas que deben sortear la Iglesia católica y la sociedad para mantenerse vinculadas.

Por otra parte, la religiosidad y la afiliación o identidad religiosa son elementos propios de la cultura, por lo que es necesario destacar su impacto en los cambios que atañen a la interrelación familia-religión. Debe acotarse que en este artículo cultura se define desde dos apreciaciones: i) como aquello que es "un fragmento finito de entre la incomprensible inmensidad del devenir del mundo, al cual se ha conferido — desde el punto de vista del hombre - un sentido y significado" (Güell, 2008, p. 49); y ii) como aquello que "denota un esquema históricamente transmitido de significaciones representadas en símbolos, un sistema de concepciones heredadas y expresadas en formas simbólicas por medios con los cuales los hombres se comunican, perpetúan y desarrollan su conocimiento y sus actitudes frente a la vida" (Geertz, 2003, p. 88). Cultura es entonces un sistema de significados que se encarnan en símbolos heredados con los que se da sentido a la realidad.

Por tanto, hay un estrecho lazo entre transmisión cultural y transmisión religiosa dentro de las familias, ${ }^{3}$ el cual da visibilidad a las reinterpretaciones

3 Como señala Meléndez "el contexto -económico, social, político, cultural e ideológico- condiciona la estructuración del campo religioso, al igual que las prácticas y los discursos que se producen y difunden 
y resignificaciones y, como resultado, a los nuevos significados de las prácticas religiosas en las familias, esto es, las celebraciones más importantes de la tradición judeo-cristiana, asistir a misa y la recepción de sacramentos. Así como la cultura es un eje rector de la socialización de los individuos, la religión también lo es en la medida en que confiere elementos compartidos por las personas, que se encuentran dotados de significados comunes (Durán, Díaz \& Valdés, s. f).

De la exposición previa se deriva la hipótesis del este artículo: la familia es la institución dentro de la cual se produce la transmisión histórica de patrones simbólicos mediante la socialización de los individuos, entregándoles elementos culturales vía una herencia religiosa. Dentro de dicha familia, las mujeres — sobre todo las madres o las mujeres que personifican esta posición de parentesco- son las que transmiten las creencias y las prácticas de la religiosidad mediante, entre otros actos, la coordinación de las celebraciones importantes, interpretadas como una de las formas posibles del trabajo de parentesco (Di Leonardo, 1987).

En el marco de lo anterior, se plantean dos subhipótesis: 1) la presunción de que, en algún punto, las trayectorias y experiencias vitales de los miembros de la familia consiguen resignificar y reinterpretar las prácticas religiosas heredadas, lo que pone de relieve la tensión que provoca el cambio social en las instituciones familiares y religiosas. (No es menester de este artículo ofrecer un panorama comparativo de la presencia religiosa entre las generaciones de una familia, sino ilustrar trayectorias personales de religiosidad a la luz de sentidos familiares comunes que operan como punto de referencia para comprender las reinterpretaciones que los individuos manifiestan.)

Y 2), que a pesar de los cambios evidentes en la estructura religiosa a nivel social, la religiosidad sigue reproduciéndose en las familias con nuevos o viejos significados, de lo que una parte importante se sustenta en asumir la creencia y la fe como una forma de practicar el cuidado, mantener el trabajo de parentesco y forjar vínculos en las familias.

En lo relativo a estas prácticas de cuidado, la transmisión de los patrones culturales religiosos no sucede en un contexto de inercia, sino que mucho responde al trabajo de parentesco realizado al interior de la familia. Este término se ha definido como "la concepción, la mantención y la celebración ritual de lazos de parentesco a través de los hogares, incluyendo visitas, cartas, llamadas telefónicas, regalos y tarjetas a los parientes, la organización de reuniones para fiestas, la creación y mantención de relaciones de cuasi parentesco, las decisiones

dentro de él, también lo es que el sistema religioso, proporciona a sus fieles una visión del mundo que, aunque sea parcialmente, orienta su comportamiento, lo que hace que el campo religioso también incida en el acontecer social" (Meléndez, 1993, p. 13). 
de abandonar o intensificar lazos en particular, el trabajo mental de reflexionar sobre todas esas actividades y la creación y comunicación de imágenes de familia y parentesco" (Di Leonardo, 1987, pp. 442-443). En su mayor parte, el trabajo de parentesco corre a cargo de las mujeres que tienen una relación jerárquica en las familias (abuelas, madres, suegras) y se traspasa y hereda a otras mujeres (Di Leonardo, 1987).

\section{Iglesia católica, religión y religiosidad en Chile}

La Iglesia católica ha sido un actor relevante en muchos de los debates sobre la familia en las últimas décadas. ${ }^{4}$ Pero su importancia data de antes. Históricamente Chile ha mantenido una estructura religiosa católica que se expresa en sus modos de organización social y sus construcciones identitarias. Ello se observa en la presencia pública de directrices religiosas conservadoras y en los constantes hábitos y símbolos católicos. Estos pueden ser de orden práctico: encomendarse a santos o rezar por algo o alguien; de orden lingüístico: el uso de modismos y frases asociados a protección, buenos deseos y esperanza; 5 o de orden relacional generando parentescos: el sacramento bautismal une a las personas por compadrazgo, entre otros. Aunque se puede afirmar la predominancia católica en la historia del país, en la década de 1960 se profundiza la secularización que ya se registraba desde fines del siglo XIX (Fernández, 2016). La modernización también ha debilitado el pacto tácito entre familia y sociedad impulsando ese proceso secular, caracterizado por un desplazamiento de lo religioso a lo privado (la familia y la intimidad de los individuos) por sobre la esfera pública (por ejemplo, el Estado) (Fernández, 2016). Los motivos que explican este cambio son externos, como el progreso del pentecostalismo y el auge de nuevos credos, e internos, es decir, que la Iglesia católica chilena nunca logró construir lo que Hervieu-Léger (2005) llama "civilización parroquial", un vínculo institucional efectivo de la experiencia religiosa, ni tampoco pudo conformar un lazo sacramental más allá del bautismo ${ }^{6}$ (Valenzuela, Bargsted \& Somma, 2013).

4 Se ha hecho visible en materias como la planificación familiar: despenalización del aborto, anticoncepción y educación sexual en establecimientos educacionales; o la aprobación de nuevos regímenes conyugales y civiles, en especial los relacionados con la unión de parejas homosexuales y el divorcio.

5 "Alabado sea Dios", "con el favor de Dios/de la Virgen", "gracias a Dios", entre muchas frases populares que además aparecen en los relatos de los entrevistados que se citan más adelante.

6 Varios católicos de nuestra muestra afirmaron que el bautismo de los hijos o las hijas es un hito en las historias familiares. Pero a la vez indican que luego de esto, el lazo con la iglesia se va desvaneciendo. 
Estos cambios se han reflejado en la declaración de adherencia religiosa de los ciudadanos. El último censo en Chile realizado en $2012^{7}$ señaló que un $67 \%$ de la población se autodeclaró como católica, un descenso de $25 \%$ en cincuenta años (en 1960 el 89\% de la población se consideraba católica). Datos comparativos de la Universidad Diego Portales indican que "durante 2005 y 2015 aumentó el número de personas que no se identifica con ninguna religión, y entre aquellos que pertenecen a una iglesia, la asistencia a servicios religiosos es cada vez menor. Esto es particularmente evidente entre católicos, quienes todavía representan una mayoría en Chile" (ICso, 2015, p. 4). Estos datos indican un cambio en la otrora hegemonía del catolicismo en el país, sin embargo, aunque no se descarta que esa religión mantenga un predominio simbólico en la articulación de comprensiones comunes entre individuos, hay quienes reconocen ethos católicos comunes allende el grado de afiliación religiosa que manifiesten.

En suma, en un contexto en el que el lugar que ocupa la religión en la sociedad está cambiando, la revisión del vínculo entre religión, religiosidad y sociedad es necesaria, lo que aquí se aborda desde el ámbito de la esfera familiar.

\section{Metodología}

El presente artículo se enmarca dentro de un proyecto Fondecyt cuyo objetivo general consistió en analizar cómo el trabajo de parentesco de hombres y mujeres para mantener sus vínculos familiares y de parentesco desencadena cambios en las familias como forma de procesar los desafíos en el Chile actual, cambios que se han identificado a partir del género, el tiempo, el espacio, los vínculos familiares y de parentesco, y el modo de nombrar a los parientes (Gonzálvez, 2013, 2016). Dicha investigación utilizó un enfoque cualitativo para dar centralidad a los sujetos desde sus prácticas y significados, lo que permite destacar la reflexividad contenida en sus relatos (Taylor \& Bogdan, 1984; Canales, 2006). Con entrevistas en profundidad se indagó en la manera en que los individuos estructuran sus trayectorias familiares. Esas entrevistas se dieron en dos momentos: en el primero se relevó la aparición inicial de prácticas y celebraciones relacionadas con la tradición judeo-cristiana, y en el segundo, las reflexiones sobre estas tradiciones, sus prácticas y su reinterpretación y resignificación a la

7 Siguiendo lo que sostienen otros estudios, por la poca fiabilidad de la metodología y la aplicación del censo de 2012, las cifras referidas aquí son solo ilustrativas de afirmaciones comparativas en relación a cifras validadas de ańos anteriores. Debe apuntarse asimismo que dichas cifras provienen de Valenzuela et al., quien, además de basarse en las estimaciones de la Encuesta Bicentenario UC-Adimark, contempla esta misma aclaración. 
luz de las trayectorias vitales de cada miembro. Así, religión y religiosidad aparecieron como categorías emergentes para el análisis al término de la investigación mencionada. Aunque el bloque de preguntas orientado a la indagación del trabajo de parentesco se enfocó en el examen de diversas prácticas, ${ }^{8}$ las preguntas relacionadas con (1) celebraciones no religiosas, (2) tradiciones y costumbres y (3) prácticas religiosas mostraron que la religiosidad se expresaba con diferencias dependiendo de la dotación de significados que el/la entrevistado/a le diera, y el papel protagonista que tuviera esta práctica en la construcción del sentimiento de pertenencia a la familia. Esto requirió que en la segunda entrevista se profundizara en esta categoría tratando de comprender cómo estas personas significaban la religiosidad y qué lugar ocupaba esta en el grupo familiar en relación a mantener ese sentimiento de unidad.

La muestra inicial se proyectó con 35 entrevistados, pero se cumplieron 33 en la primera etapa (entre octubre de 2012 y septiembre de 2013) y 26,9 en la segunda (entre octubre de 2013 y septiembre de 2014). Se optó por una selección muestral teórica, la cual privilegia, entre otros criterios, que los informantes tengan características poblacionales relevantes e ilustrativas acerca del problema de investigación (Glaser \& Strauss, 1967). De esta forma se incluyeron a mujeres y hombres de distintas edades a partir de los dieciocho años, diversas orientaciones sexuales y formas familiares — solteros, parejas casadas y convivientes, con y sin hijos, y con hijos adultos fuera del hogar-, y diferentes niveles socioeconómicos (bajo, medio y alto), aunque todos residentes de la ciudad de Santiago de Chile. Entrevistadas y entrevistados fueron ubicados con el método de bola de nieve, el cual inició con los contactos de las investigadoras los que, a su vez, recomendaron a otros conocidos guiándose por los criterios de selección ya mencionados. El contacto con los informantes se hizo mediante correo electrónico y comunicaciones telefónicas, para luego pactar entrevistas en sus hogares u oficinas, lo más recurrente, o en cafeterías de la ciudad, en menor medida.

De las entrevistas de la primera etapa, en 16 casos se recolectó información relevante sobre la religión como categoría personal y familiar en tanto conservación de celebraciones e hitos, los cuales se profundizaron en la segunda entrevista pero enfatizando en la religiosidad contenida en la categoría de religión.

8 Celebraciones no religiosas, tradiciones y costumbres, prácticas religiosas, visitas, llamadas telefónicas, envío de cartas, correos electrónicos, uso de Twiter, Facebook o chat, videoconferencias, envío o recepción de regalos, entrega de tarjetas de recuerdo, préstamos de dinero, remesas económicas (migrantes), dar cuidados, recibir cuidados y otras formas de mantenimiento de los vínculos y acontecimientos familiares.

9 La reducción de entrevistas de 33 a 26 se debió a que algunos informantes dejaron el país o no pudieron ser localizados, lo cual se condice con las dificultades de usar una metodología longitudinal. 
En este sentido, la tradición más mencionada fue la celebración de la Navidad y el credo más repetido fue el católico. Asimismo se halló que las familias de los entrevistados eran variadas y diversas: las hay que se componen de católicos, de otros credos y espiritualidades —el protestantismo (evangélicos, mormones y luteranos), el judaísmo o la ancestralidad indígena (cosmovisión y ritos mapuches) - y por miembros que no se declaran creyentes en dioses ni practicantes de espiritualidad alguna. Y las hay donde los miembros se declaran católicos, pero "a su manera", es decir, aplicando el quienes creen sin pertenecer ni participar en una religión.

\section{Resignificación y reinterpretación de prácticas religiosas tradicionales: relaciones entre identidad y práctica religiosa}

Un primer apunte es que la mayoría de los entrevistados declararon practicar un catolicismo que no necesariamente es compartido por toda la familia. Este es el caso de Beatriz, ${ }^{10}$ de 35 años de edad. Al preguntarle si la religión era importante para su familia, señalaba: "Para mí sí, para mis hijos... no mucho. Como son gente joven, entonces no están muy ligados a... Son católicos sí, pero no están muy ligados ahí, ni a la misa y todas esas cosas" (Entrevista, julio de 2014).

En este discurso destacan dos planos relacionados con el elemento generacional: los adultos que asisten a misa, y lo jóvenes que no lo hacen y que se han distanciado del catolicismo, aunque no de la creencia. El primer plano se ha registrado teóricamente con el estudio del efecto generacional:

Cada generación es portadora de un nivel de religiosidad más bajo que la anterior... El efecto de edad es prácticamente inexistente, lo que significa que la preferencia o intensidad de la religiosidad se mantiene con los ańos y resulta poco afectada por los ciclos de vida. La hipótesis de que el sentimiento religioso se acrecienta con la edad es un efecto espejo del efecto generacional que indica que las generaciones precedentes —y por ende más adultas— son sistemáticamente más religiosas que las siguientes y más jóvenes, lo que entrega una impresión errónea de que la religiosidad aumenta cuando se envejece (Valenzuela, Bargsted \& Somma, 2013, p. 5).

10 Forma familiar nuclear. Cabe mencionar que Cicerchia (1999) propone que cuando se haga referencia a la familia se emplee el concepto de "formas familiares" dado que se trata de una organización que como sujeto histórico complejo es receptora de cambios y de determinantes sociales. Adoptar dicho concepto en nuestra investigación nos permite dar voz a la perspectiva de los sujetos entrevistados/as y aproximarnos a la definición de familia con la que ellos se identifican, agrupando de esta forma una amplia diversidad de acuerdos familiares. 
Algo similar declara Blanca, ${ }^{11}$ de 43 años. Ella relata que a pesar de que ha disminuido su asistencia, ir a misa "es como... más estar consigo mismo". Explicaba que asiste menos por la sensación de que es más difícil ir cuando no se tiene compañía: "uno siempre se hace la idea como de ir con otra persona". Y aclaraba que sus hijos no participan de la misa, pues uno "cree a su manera". Además Blanca tiene reparos por las contradicciones que detecta entre la prédica y la práctica de la institución, a lo que suma que advierte que se trata de un hábito que se ha diluido en el tiempo debido a que se han superado ciertas etapas familiares:

Mis hijos están preparados, hicieron su primera comunión y todo, menos confirmación. En ese entonces nosotros, para prepararnos, teníamos que asistir a catequesis. Ahí íbamos los dos con mi marido y ya teníamos como un hábito de ir todos los martes a la catequesis, después ir los sábados, era como una necesidad. O sea el alma de uno necesita como eso de ir. Y ya, bueno, ya hicieron la primera comunión, y como que ya eso se fue dilatando un poco (Entrevista, junio de 2014).

Estos dos factores ilustran de qué modo las prácticas religiosas, como asistir a misa, se transforman entre generaciones en una misma familia; sin embargo, la religiosidad de los miembros que la integran no necesariamente se altera: los hijos de Beatriz y Blanca pertenecen al grupo de quienes creen sin participar, lo que es explicado por ellas a la luz de sus propias experiencias, trayectorias y apreciaciones respecto de la Iglesia y la religión en la que fueron formados. Un tercer factor para Blanca es el tiempo disponible, y que también no tiene compañía. Como empleada del hogar en varias casas particulares, ella refería: "Como yo trabajo, son cuatro casas con la mía, por decirlo así, ya como que acabo agotada. Yo tengo una parroquia cerquita de mi casa po', será como unas dos cuadras más menos. Pero eso, la misa la hacen a las ocho y claro, sola no voy a ir" (Entrevista, junio de 2014).

Esto muestra que las transformaciones y cambios sociales —las dinámicas laborales, el uso del tiempo- inciden en la participación religiosa, pero no impiden la transmisión religiosa en la familia como una forma de socialización, o como un refugio ante dichos cambios. Esto lo ejemplifica Francisca, ${ }^{12}$ una mujer de 56 años, para quien ir a misa es "mi punto de escape... Entonces, yo creo que es el minuto en que, que yo lo considero como mío. A lo mejor, no sé, una hora o qué sé yo, lo que dure ese tiempo en mî" (Entrevista, junio de 2014). Un mecanismo de refugio individual que se extiende a la esfera familiar

11 Forma familiar nuclear.

12 Forma familiar nuclear. 
cuando todos los miembros del núcleo son convocados a la asistencia a misa en algún punto, incluso aquellos que no profesan la fe. El marido de Francisca es ateo, pero ella señalaba que se ha integrado, aunque con dificultad.

Para otras personas, como Emilia ${ }^{13}$ o Cristina, ${ }^{14}$ ir a misa no está relacionado con ser más o menos católica. Emilia, de 35 años, destaca que independientemente de que no vaya todos los domingos a misa, reza mucho. Su argumento es que "no necesitas ir a misa todos los domingos, si realmente tienes fe de lo que a ti te enseñaron, porque es lo que a ti te educaron" (Entrevista, junio de 2014). Para Emilia esta creencia está claramente mediada por la educación impartida por su madre, y añade que "si me hubieran educado musulmana quizás sería musulmana, o judía, no sé” (Entrevista, junio de 2014). Cristina, de 35 años, es de la misma opinión, esto es, que más allá de ir o no a misa, su familia y el colegio donde estudió le transmitieron valores: "Mi familia es católica, fuimos criados en colegio católico, de ahí sacamos valores que yo creo que permanecen en nosotros, siendo que ya ninguno de mis hermanos — bueno, mi hermana tiene a sus hijos en un colegio católico- - pero ya no vamos a misa ni nada de eso, pero sí valoramos, por ejemplo, ejemplos que nos ha dado el catolicismo o Jesucristo como la humildad" (Entrevista, agosto de 2014).

Las reinterpretaciones en estos relatos dan luces del funcionamiento de las categorías de religiosidad e identidad religiosa en las familias, mostrando que existen prácticas voluntariamente elegidas relacionadas con comportamientos y valores cristianos, y prácticas que responden a una herencia cultural, transmitida usualmente por una mujer. Así, pese a los cambios, tensiones y transformaciones intergeneracionales, la religiosidad se sigue reproduciendo dentro de la esfera familiar como un modo de transmisión cultural, otorgando a sus miembros elementos y significados comunes, entre estos, hábitos y valores.

Resignificación de las celebraciones tradicionales: Navidad como espacio de reunión y de trabajo de parentesco

Ante la pregunta sobre las celebraciones se observó que hay momentos de encuentro y reunión familiar que giran en torno a tradiciones religiosas, en especial católicas, por ejemplo, la Navidad. Son prácticas que en algunos de los casos se consignan como religiosas, pero en otros no. Emilia ${ }^{15}$ lo detallaba: "Nosotros nos juntamos para las navidades, es importante la Semana Santa, porque eso

\footnotetext{
13 Forma familiar extensa.

14 Forma familiar unipersonal.

15 Forma familiar extensa.
} 
también te une. Son, son fiestas que te unen, si tú quieres. Han sido importantes en la vida de nuestra familia" (Entrevista, junio de 2014).

Claudia ${ }^{16}$ y Tatiana ${ }^{17}$ también referían la presencia de un espíritu de reunión alrededor de la Navidad, sin embargo, la desligan del cariz religioso y se inscriben en el grupo de los que creen sin pertenecer. Claudia decía durante la primera entrevista ${ }^{18}$ que la Navidad era una celebración religiosa, pero en la segunda, al preguntársele en profundidad, respondía:

No sé por qué la metí en lo religioso, mmm... o sea, a nosotros nos encanta la Navidad porque nos juntamos y eso, no es como que hagamos algo específicamente religioso. No sé en verdad por qué la puse en lo religioso, no es que recemos ese día. Sí, a mi mamá a veces se le ocurre decir como "oye, pero acordémonos que esto es como el nacimiento de Jesús” y es como que “jajajá, sí”. No, somos cero, cero religiosos en mi familia (Entrevista, agosto de 2014).

Tatiana siguió el mismo patrón, en la primera entrevista ${ }^{19}$ sostenía que la Navidad era una celebración religiosa, pero en la segunda, corrigió y al preguntarle qué había de religioso en sus celebraciones, confesaba: “SSabes qué?, la verdad, no sé mucho (risas). Porque mi familia no es católica, católica, pero sí creyente, y mis abuelos eran muy creyentes. Entonces yo creo que fue como por tradición. Ahora, si tú me preguntai' si mis primos son católicos, no, yo creo que, $\mathrm{mmm}$... la mitad son ateos, pero igual se juntan y sienten que es algo como sagrado (risas), entre comillas" (Entrevista, junio de 2014).

Para Mario, ${ }^{20}$ de 34 ańos, la Navidad es un espacio de reunión, de recogimiento y catarsis, sobre todo para su madre. Destaca que en esta celebración casi no tienen invitados porque: "Es lo familiar, pero lo familiar más íntimo. El Año Nuevo no, ahí se hace asado y se invita a otra gente y es como... compartir. Mi mamá por lo menos, que es como la que 'lleva la viruta ahí', se toma muy en serio ese tema como del recogimiento y todo eso" (Entrevista, junio de 2014).

Los tres casos ilustran que, al igual que asistir a misa, celebrar un evento de raigambre religiosa se estima como un momento de socialización para las familias en tanto es un espacio para reunirse y compartir. En la resignificación de la $\mathrm{Na}$ vidad como fecha de reunión familiar, las dinámicas familiares se tensionan por los preparativos de la celebración y por las negociaciones en torno a la reunión.

\footnotetext{
Forma familiar monoparental.

Forma familiar extensa.

En abril de 2013.

En mayo de 2013.

20 Forma familiar nuclear.
} 
En cuanto a la organización de los preparativos, estos tienen encargados relativamente fijos a lo largo de los años. Según los entrevistados, hay un reparto de ciertas funciones; sin embargo, en su mayor parte quedan en manos de mujeres mediante el trabajo de parentesco (Di Leonardo, 1987); son ellas quienes organizan el encuentro y las que congregan a la familia. En esta organización adquiere relevancia el género, y disposiciones como el lugar físico del encuentro que, en general, depende de la decisión de la madre.

Acerca de ello, en su primera entrevista, Cristina señalaba que su madre, su hermana y la suegra de esta se encargan de la cena de Navidad y que los demás participantes tienen tareas muy menores. Al consultarle qué motiva esto, respondía:

Mira, tengo una anécdota, mi mamá siempre habla de que su abuelita, su orgullo era ser dueńa de casa, ¿ya?, entonces cuando nació mi hermana, su abuelita le dijo "usted ya tiene a su dueña de casa", porque su orgullo máximo era ser dueńa de casa. A lo que voy es que mi mamá, mi mamá es profesional y se reía un poco de esta fascinación que tenía su abuelita por ser dueña de casa, pero a la vez le otorga un valor súper importante, ¿cachai?, entonces mi hermana quedó estipulada, hasta el día de hoy le dicen "la dueña de casa", y además que le gusta. Como que lo heredó también de las hermanas de mi papá, que son híper súper híper buenas dueñas de casa, ¿ya? Mi mamá es dueńa de casa por deber prácticamente, porque no es tan buena, y la mamá de mi cuñado es híper buena dueña de casa, entonces ellas son las dueñas de casa que se preocupan de eso (Entrevista, agosto de 2014).

Este relato coincide con lo que sostiene Di Leonardo (1987) sobre la supuesta naturalización del vínculo entre el ser mujer y el ser responsable de la organización de actividades relacionadas con las posiciones de parentesco que las mujeres ocupan en la familia, lo que muchas veces se traduce en que para que se dé un contacto entre parientes o la celebración de fiestas como la Navidad, debe haber una mujer adulta en el hogar que sea la responsable. Esta figura protagonista ha sido denominada kinkeeper, es decir, la persona encargada de mantener el contacto entre miembros de las familias, y que ejerce funciones de cuidado que según Gerstel \& Gallagher (1993) no están libres de angustia y malestar, debido al alto costo emocional y psicológico que implica ocupar este rol, en particular cuando es por motivos normativos y no por voluntad.

En relación con las negociaciones en las familias para celebrar la Navidad, Mario, Pedro y Cristina destacaban diversos arreglos familiares que responden a las trayectorias vitales de los integrantes de la familia y a la interpretación del sentido de dicho festejo. En el caso de Mario, su padre mantenía dos familias paralelas a través del tiempo y su hermana comenzaba su familia con su pareja 
y su hijo. Así, la negociación para celebrar la Navidad transcurre de la siguiente forma:

Mi papá hace, no sé, hace uno o dos años atrás, ya no pasa la fiesta de Navidad ni de Año Nuevo con nosotros. Antes, claro, en la Navidad se quedaba con nosotros y el Año Nuevo en general lo pasaba él en su casa con su familia... No sé, lo empezaron a apretar del otro lado. Aparte, mi hermana, por ejemplo, la última Navidad no estuvo con nosotros, la pasó con su familia. No sé si mi hermana habrá negociado con su pareja el hecho de estar con nosotros por ejemplo o no, desconozco eso, pero sí por lo menos el tema de con quién se va a pasar la Navidad es un tema en mi casa. O sea, mi mamá pregunta a mi hermana, por ejemplo, "oiga mijita... ¡̇con quién va a pasar la Pascua?” y mi hermana, no sé, quizás le dice "no, la voy a pasar en la casa y después de las doce me voy a tu casa", que es lo que pasa en general, ella cena con su familia que es, básicamente la pareja que tenía y su hijo, y después se va pa' la casa donde estamos nosotros (Entrevista, junio de 2014).

Pedro acotaba que han tratado de que la Navidad sea en familia, por ser la fiesta favorita de su madre y porque es ella quien congrega, pero matizaba diciendo que su festejo tiene muy poco de religiosidad y más de reunión, además de un tanto de consumo.

Mira, ha variado los dos, tres últimos años porque tengo dos hermanas que tienen hijos, tengo una tercera que va a tener un hijo también. Entonces ellos han tenido que también generar, o su propia Navidad, o Navidad en la familia de los otros padres, o sea, de los otros abuelos. Entonces eso ha tendido a cambiar, pero en general está la intención de hacerlo. Entonces, es más de afecto, de compartir, y los mismos sobrinos han cambiado un poco el giro de la Navidad, lo han instalado también en el tema de la importancia de los regalos (Entrevista, junio de 2014).

Creencia y religiosidad: la transmisión de identidad a través del género

Las mujeres fueron se mencionaron reiteradamente como las "encargadas" de la mantención y la reproducción de las celebraciones mediante el trabajo de parentesco (Di Leonadro, 1987; Gonzálvez, 2016). En este apartado se detalla cómo ellas son también las encargadas del sentido religioso dentro de las familias.

Beatriz se identifica a sí misma como la encargada de la religión en su familia, por sobre su marido. Mientras que Emilia explica que, aunque hija de católica y luterano, fue su madre quien la educó en el catolicismo. De hecho su madre fue excomulgada tras su matrimonio a través de otro credo, "nosotros nos educamos 
en la fe católica porque ella —mamá- nos inculcó la fe católica”. Sin embargo repite la historia de su madre: a su marido "no le gusta la religión católica, ni los curas, ni nada de eso" (Entrevista, junio de 2014), pero ella se declara como una mujer muy religiosa, lo que la llevó a educar a su hija en un colegio católico. El resultado es que su hija manifiesta la fe, pero no la práctica.

Siguiendo el modelo de la madre que transfiere las creencias, Silvia, ${ }^{21}$ de 38 años, indicaba que había sido criada en una familia católica y que para ella era importante creer, aunque fuera algo difícil. Por eso decidió educar a sus hijas en la misma fe llevándolas a un colegio católico, yendo a misa y compartiendo con ellas prácticas como el rezo por las noches. Además, declaraba que esto era importante porque "les voy a entregar un mundo en que hay creencias, pero finalmente no las voy a obligar a creer en algo" (Entrevista, junio de 2014). Esta educación ha dado resultados disímiles: una hija se interesa en las enseñanzas religiosas, pero la otra las toma con un poco de tedio y tiende a cuestionarlas.

Mario sostenía que el tema de la religión es interesante, sobre todo porque su madre es muy creyente y él percibe que ella "ha sabido inculcar esa misma ética, por ejemplo, en mi hermana mayor, entonces ahí entre ellas, yo creo que creen y piensan y actúan religiosamente de manera muy similar" (Entrevista, junio de 2014). En su caso, la religiosidad es también una práctica de su padre, tanto que Mario afirma que su padre es muy bueno con los santorales y que siempre lo llama en su día para saludarlo. Incluso lo sigue llamando en la misma fecha, a pesar de que su nombre ya se eliminó del santoral.

Junto con el relato de Cristina citado arriba referente a la transmisión de valores, las narraciones de vida familiar dan cuenta de un vínculo entre familia y religiosidad, lo cual se relaciona a la transmisión de símbolos que doten de sentido a los miembros de la familia. Las instituciones familiares y religiosas pueden reforzarse por medio del apoyo social o del control social (D'Antonio, Newman \& Wright, 1982). Los relatos expuestos son ejemplo de cómo opera dicho apoyo social, dado que la religión provee de normas, valores y significados familiares (D’Antonio 1980; D’Antonio, Newman \& Wright, 1982).

\section{Presencia de otros credos y tradiciones}

Juan Carlos, Flor y Fabián no son católicos. Juan Carlos practica un judaísmo que se relaciona estrechamente con su sentido de comunidad, debido a que se entrelaza con su identidad sexual y con sus intereses de estudio. Él traduce su religiosidad del siguiente modo:

21 Forma familiar monoparental. 
Tengo una identidad que es para asumirla y no para esconderla, también siento una identidad judía, que viene desde mi niñez, que en algún momento a lo mejor se quebró, pero por eso forma parte de mi pertenencia, entonces de alguna manera esa identidad judía a través de las fiestas, a través de la comunidad o de la sinagoga, en fin, me significa a mí también un sentido de vida, le da más sentido a mi vida. Lo espiritual, que yo creo que es bastante importante y que yo necesito dar a retomar, de hecho, quiero recuperar el contenido judío (Entrevista, abril de 2014).

En contraste con los entrevistados católicos que asisten a su iglesia, para Juan Carlos, de 54 años de edad, ir a la sinagoga es importante y aunque, como Blanca, nadie lo acompaña, él encuentra en la sinagoga una comunidad. Él asimismo relata que esta sensación es tan fuerte que luego de cambiar de congregación decidió volver a la misma, pues advirtió que su sentimiento de pertenencia lo mediaba el lugar donde estuviese su rabino y aquel donde a través de la diversidad podía reconocerse en comunidad.

Flor aclaraba que su familia no mantiene prácticas religiosas, pero sí prácticas espirituales recuperadas y relacionadas con sus orígenes indígenas:

Yo creo que son cosas nuevas que se van incorporando, o cosas rescatadas, recuperadas. La ancestralidad mapuche - porque yo no sé si lo menciono, que tengo origen mapuche, en la entrevista pasada-. Ahora lo veo así, lo resumo así, como que son cosas que se van incorporando, y que son condimentos y alińos para toda tu vida, y que, si es personal, también puede ser un poco colectivo (Entrevista, mayo de 2014).

Por su parte, Fabián ${ }^{22}$ es sin duda el caso de mayor diversidad religiosa a nivel intrafamiliar: su madre es católica, su padre también, pero no se declara como practicante y es cercano a la ancestralidad mapuche, su hermano mayor es mormón y su hermana menor adscribe a la ancestralidad mapuche. Él, por su parte, afirma que es creyente, pero no en dioses. Sin embargo, esta diversidad no siempre se manifestó en su familia: durante mucho tiempo, la madre de Fabián los instó a participar del rito católico durante la Navidad, pero con el tiempo esto menguó y se transformó. Fabián lo explicaba: "Cuando se detuvo [la celebración tradicional de la Navidad], fue básicamente cuando dejamos de adscribir digamos a, ni siquiera a la práctica religiosa en sí, sino como dijimos: 'pucha, vieja, sabís' que buena onda, pero no comulgamos con eso'” (Entrevista, julio de 2014). Sin embargo, él indica que actualmente realiza prácticas religiosas pero ligadas a la ancestralidad mapuche: "Somos de ascendencia mapuche,

22 Forma familiar extensa. 
entonces mi hermana es como la que vive en una ruca, ¿cachai?, y como que tiene un ceremonial al respecto y todo, una forma de entender el mundo al respecto, y ella es la que lleva ahora una ritualidad a la casa, ¿cachai? a eso me refiero con las ceremonias religiosas, donde no sé po', donde mi 'viejo' está como bien metido también, ¿̨achai?" (Entrevista, julio de 2014).

La inclusión de estos casos se debe a tres motivos. El primero es porque con ellos se detecta un patrón común en las familias más allá del credo que profesen. Este patrón se articula con la mantención de una transmisión cultural a través de la religiosidad, la cual puede incluir reinterpretaciones ante los desafíos a lo tradicional o del sincretismo.

El segundo, porque tanto Juan Carlos como Fabián, viven una religiosidad transmitida por sus madres, las cuales se encargan de los preparativos y de inculcarles un sentido de fe que trasciende a sus decisiones de adultos en relación a su identidad religiosa. Al igual que con los católicos, sus experiencias $\mathrm{y}$ trayectorias les permiten reinterpretar las estructuras religiosas aprehendidas originalmente en sus familias.

Y tercero, porque Flor y Fabián muestran cómo el debilitamiento del pacto tácito entre familia y sociedad, y de religión y sociedad, les dan la pauta para recuperar los sentidos y significados asociados a lo ancestral. Estas familias siguen una dinámica de refugio ante el cambio, lo que les permite una forma religiosa plural y diversa, diferente intergeneracionalmente, pero orientada hacia un objetivo similar de las familias católicas: la unión de los miembros mediante la reunión, el sentido de pertenencia e identidad, y la presencia de un ethos común. Así, y para todos los ejemplos en este artículo, la fe expresada en la categoría de religiosidad es un elemento movilizador de sentidos más allá de un credo o institución.

\section{Conclusiones}

Debido a la emergencia de las prácticas religiosas como un resultado no esperado en el transcurso de nuestra investigación, nos propusimos profundizar en ellas por su protagonismo en el trabajo de parentesco. El análisis de las entrevistas da cuenta de que la vivencia de la religiosidad por parte de los/as entrevistados/as —ya fuera significada como práctica declaradamente religiosa, o estuviera alejada de este cariz - ofrece una gama de significaciones que van de la continuidad de la práctica religiosa o su reinterpretación, hasta la convivencia de diferentes religiones en una misma unidad familiar. La religiosidad y sus interpretaciones al interior de las familias experimentan tensiones que son parte de cambios socioculturales más amplios que afectan a Chile en 
su conjunto, por eso celebraciones tradicionales como asistir a misa o la $\mathrm{Na}$ vidad actualmente se conciben más como reuniones familiares desligadas de lo religioso y orientadas a lo personal, al compartir, o al consumo. Los casos presentados ilustran que la familia es una institución en la que se transmiten patrones simbólicos por medio de la herencia religiosa, y que son las mujeres — sobre todo las madres — quienes se encargan de dicha transmisión y de organizar los actos que conlleva.

Sin embargo, es posible rastrear dentro de las familias que cada generación, mediada por sus trayectorias y experiencias, consigue dar nuevas interpretaciones y significados, o incluso desafía las prácticas religiosas heredadas. Esto no supone la desaparición de la religiosidad, más bien evidencia su dinamismo. Así, la religiosidad se sigue reproduciendo dentro de las familias haciendo frente a tensiones y cambios sociales. Los hallazgos de este artículo indican una interrelación viva entre familia y religiosidad, por lo que si una de las dos cambia, la otra se verá impactada y viceversa. Ante esto, es necesario que futuras investigaciones atiendan el vínculo entre ambas esferas y exploren otros cambios en las familias, observando cómo operaría el factor religioso en ellos. Sin duda que podría constatarse que áreas como la organización social de los cuidados y las "nuevas" formas de parentesco se afectan por la interrelación entre familia, religión, religiosidad e identidad religiosa.

\section{Referencias}

Allen, K. (2000). A conscious and inclusive family studies. Journal of Marriage and Family, (62), 4-17. doi: 10.1111/j.1741-3737.2000.00004.x

Araujo, K. (2005). Vida cotidiana y transformaciones de género: la esfera doméstica. Revista de la Academia, (10), 77-117. Recuperado el 5 de junio de 2016, de http:/www.academia.cl/ biblioteca/publicaciones/Academia_10/Vidacotidianaytransformacionesdegenero.pdf

Araujo, K. \& Martuccelli, D. (2012). Desafios comunes: retrato de la sociedad chilena y sus individuos. Santiago de Chile: Lom Ediciones.

Arriagada, I. (2002). Cambios y desagualdad en las familias latinoamericanas. Revista CEPAL, (77), 143-161. Recuperado el 1 de junio de 2016, de http://repository.eclac.org/bitstream/ handle/11362/10829/077143161_es.pdf?sequence=1\&isAllowed $=y$

Canales, M. (2006). Metodologías de investigación social. Introducción a los oficios. Santiago de Chile: LOM Ediciones. 
Cicerchia, R. (1999). Alianzas, redes y estrategias. El encanto y la crisis de las formas familiares. Nómadas, (11), 46-53. Recuperado el 20 de mayo de 2019, de http://nomadas.ucentral .edu.co/index.php/inicio/38-las-familias-contemporaneas-nomadas-11/901-alianzas-redes -y-estrategias-el-encanto-y-la-crisis-de-las-formas-familiares

Comisión Económica para América Latina y el Caribe (CEPAL). (2011). Panorama Social de América Latina. Santiago de Chile: CEPAL.

Comisión Económica para América Latina y el Caribe (CEPAL). (2009). Panorama Social de América Latina. Santiago de Chile: CEPAL.

Comisión Económica para América Latina y el Caribe (CEPAL). (2008). Panorama Social de América Latina. Santiago de Chile: CEPAL.

Comisión Económica para América Latina y el Caribe (CEPAL). (1994). Familia y futuro: un programa regional en América Latina y el Caribe. Santiago de Chile: Naciones Unidas.

Cruz Santos, M. (s. f.). La religiosidad popular como elemento de identidad cultural en la América Latina contemporánea. (Documento de Trabajo). Puerto Rico: Sistema Universitario Ana G. Méndez.

D’Antonio, W. (1980). The Family and Religion: Exploring a Changing Relationship. Journal for the Scientific Study of Religion, 19(2), 89-104.

D’Antonio, W., Newman, W. \& Wright, S. (1982). Religion and Family Life: How Social Scientists View the Relationship. Journal for the Scientific Study of Religion, 21(3), 218-225. doi: $10.2307 / 1385887$

Daly, M. \& Lewis, J. (2000). The concept of social care and the analysis of contemporary welfare states. The British Journal of Sociology, (51), 281-298. doi: 10.1111/j.1468 $-4446.2000 .00281 . x$

Di Leonardo, M. (1987). The female world of cards and holidays: women, families and the work of kindship. Signs: Journal of Women in Culture and Society, 12(3), 440-453.

Durán, A., Díaz, M. \& Valdés, Y. (s. f.). Religiosidad y socialización en la familia. La Habana: CLACSO.

Fernández, M. (2016). Cambio histórico, sociedad secular e Iglesia: Interpretaciones del mundo católico ante un contexto de transformación. Chile, 1960-1964. Teología y vida, 57(1), 39-65. 
Ferree, M. (2010). Filling the glass. Gender perspectives of families. Journal of Marriage and Family, (72), 420-439. Recuperado el 2 de enero de 2016, de http://www.ssc.wisc .edu/ $\sim$ mferree/documents/jomf_final.pdf

Frazer, J. G. (1922). The Golden Bough: A study in magic and religion. Nueva York: Macmillan.

Geertz, C. (2003). La interpretación de las culturas. Barcelona: Gedisa.

Gerstel, N. \& Gallagher, S. K. (1993). Kinkeeping and distress: gender, recipients of care and work-family conflict. Journal of Marriage and Family, 55(3), 598-607.

Glaser, B. \& Strauss, A. (1967). The Discovery of Grounded Theory: Strategies for Qualitative Research. Nueva York: Aldine Press.

Gonzálvez, H. (2016). Diminutivos, hipocorísticos y otras formas de nombrar a los parientes en familias de Santiago de Chile. Revista de Dialectología y Tradiciones Populares, LXXI(1), 215-232.

Gonzálvez, H. (2015). Diversidades familiares, cuidados y migración. Nuevos enfoques y viejos dilemas. Santiago de Chile: Universidad Alberto Hurtado.

Gonzálvez, H. (2013). La producción científica sobre la familia en Chile: miradas desde la antropología feminista. La Ventana, 4(38), 88-121. Recuperado el 5 de enero de 2016, de http:// www.scielo.org.mx/scielo.php?pid=S1405-94362013000200005\&script=sci_arttext

Gutiérrez, E. \& Osorio, P. (2008). Modernización y transformaciones de las familias como procesos del condicionamiento social de dos generaciones. Última Década, 16(29), 103-135.

Güell, P. (2008). ¿Qué se dice cuando se dice cultura? Notas sobre el nombre de un problema. Revista de Sociología, (22), 37-64. Recuperado el 14 de noviembre de 2015, de https:// revistadesociologia.uchile.cl/index.php/RDS/article/view/14476

Güell, P. (1999). Familia y modernización en Chile. (Exposición ante la comisión de expertos en temas de familia SERnam). Santiago de Chile.

Hervieu-Léger, D. (2005). La Religión, hilo de la memoria. Herder: Barcelona.

Instituto de Investigación en Ciencias Sociales (ICSO). (2015). Religión y Política en Chile. En ICso (Eds.), Tendencias Encuesta Nacional UDP 2005-2015 (pp. 1-46). Santiago: Universidad Diego Portales.

Lenski, G. (1963). The religious factor: A Sociological Study of Religion's Impact on Politics, Economics, and Family Life. Garden City, N. Y.: Doubleday. 
McAndrew, S. \& Voas, D. (2011). Measuring religiosity using surveys. Survey Question Bank. Topic Overview, (4), 1-15. Recuperado el 15 de enero de 2016, de https://www.ukdataservice .ac.uk/media/263004/discover_sqb_religion_mcandrew_voas.pdf

McDowell, T. \& Fang, S.R. (2007). Feminist-informed critical multiculturalism. Journal of Family Issues, 28(4), 549-566. Recuperado el 15 de enero de 2016, de http://journals.sagepub .com/doi/10.1177/0192513X06297331

Meléndez, G. (1993). Iglesia y sociedad en la actual coyuntura centroamericana. Perfiles Latinoamericanos, 1(2), 7-50. Recuperado el 6 de marzo de 2016, de http://perfilesla.flacso.edu .mx/index.php/perfilesla/article/view/481/434

Ortiz, F. (2015, 27 de julio). La "Familia” en la legislación chilena: ¿¿de qué familia estamos hablando? Red Seca. Recuperado el 7 de marzo de 2016, de http://www.redseca.cl/la-familia -en-la-legislacion-chilena-de-que-familia-estamos-hablando/

Petts, R. (2007). Religious participation, religious affiliation, and engagement with children among fathers experiencing the birth of a new child. Journal of Family Issues, 28(9),1139-1161. Recuperado el 5 de junio de 2016, de http://journals.sagepub.com/doi/ abs/10.1177/0192513X07300788

Programa de las Naciones Unidas para el Desarrollo (PNUD). (2013). Informe regional de desarroIlo humano 2013-2014. Santiago de Chile: Naciones Unidas.

Programa de las Naciones Unidas para el Desarrollo (PNUD). (2002). Nosotros los chilenos: Un desafio cultural. Recuperado el 6 de marzo de 2016, de http://www.cl.undp.org/content/ dam/chile/docs/desarrollohumano/undp_cl_idh_informe_2002.pdf.

Ramos, C. (1998). La familia en la investigación social en Chile. (Documento de Trabajo, núm. 56). Santiago de Chile: SERNAM.

Reca, I. (1993). La familia chilena en los noventa. Santiago de Chile: SERNAM.

Salazar Parreñas, R. (2005). Long distance intimacy: class, gender and intergenerational relations between mothers and children in Filipino transnational families. Global Networks, 5(4), 317-336.

Taylor S. J. \& Bogdan, R. (1984). Introducción a los métodos cualitativos de investigación. Barcelona: Paidós.

Thornton, A. (1985). Reciprocal Influences of Family and Religion in a Changing World. Journal of Marriage and Family, 47(2), 381-394. doi: 10.2307/352138 
Valdés, X. (2007). Notas sobre la metamorfosis de la familia en Chile. Ponencia presentada en la Reunión de Especialistas. Futuro de las familias y desafíos para las políticas públicas. Santiago, 22-23 de noviembre.

Valdés. X. \& Godoy, C. G. (2008). El lugar del padre: rupturas y herencias. Representaciones de la paternidad en grupos altos, medios y populares chilenos. Revista Estudios Avanzados, 6(9), 79-112. Recuperado el 11 de enero de 2016, de http://menengage.org/wp-content/ uploads/2014/06/lugar-del-padre.pdf

Valdés, X. \& Valdés, T. (2005). Familia y vida privada. ¿Transformaciones, tensiones o nuevos sentidos? Santiago: Flacso Chile/Cedem.

Valenzuela, E., Bargsted, M. \& Somma, N. (2013). ¿En qué creen los chilenos? Naturaleza y alcance del cambio religioso en Chile. Temas de la Agenda Pública, 8(59), 1-20. Recuperado el 15 de enero de 2016, de https://repositorio.uc.cl/bitstream/handle/11534/2921/612922 .pdf?sequence $=1$

Valenzuela, J. S., Tironi, E. \& Scully, T (Eds.). (2006). El eslabón perdido. Familia, modernización y bienestar en Chile. Santiago de Chile: Taurus.

Walker, A. (2000). Refracted knowledge: viewing families through the prism of social science. Journal of Marriage and the Family, 2(3), 595-608. doi: 10.1111/j.1741-3737.2000.00595.x

Wilcox, W. B., Chaves, M. \& Franz, D. (2004). Focused on the Family? Religious Traditions, Family Discourse, and Pastoral Practice. Journal for the Scientific Study of Religion, 43(4), 491-504. Recuperado el 5 de marzo de 2016, de https://www.researchgate.net/profile/W_ Wilcox/publication/227712833_Focused_on_the_Family_Religious_Traditions_Family _Discourse_and_Pastoral_Practice/links/0deec521df8daa4aac000000.pdf

Zimmerman, C. (1973). Family and Religion. Social Science, 48(4), 203-215. 